Review Article

\title{
TISSUE CONDITIONERS : A REVIEW
}

\section{Anupama Prasad D. ${ }^{1}$, B. Rajendra Prasad ${ }^{2}$, Veena Shetty ${ }^{3}$, C.S. Shastry ${ }^{4} \&$ Krishna Prasad D. ${ }^{5}$}

${ }^{1}$ Lecturer \& Research Scholar, ${ }^{2}$ Principal \& Dean and Research Guide, ${ }^{5}$ Professor \& H.O.D, Department of Prosthodontics, A.B. Shetty M emorial Institute of Dental Sciences, ${ }^{3}$ Associate Professor, Department of Microbiology, K.S. Hegde Medical Academy, ${ }^{4}$ Principal, Nitte Gulabi Shetty M emorial Institute of Pharmaceutical Sciences, Nitte University, Deralakatte, M angalore - 575 018, Karnataka, India.

\author{
Correspondence : \\ Anupama Prasad D. \\ Lecturer/ Research Scholar, Department of Prosthodontics, A.B. Shetty M emorial Institute of Dental Sciences, \\ Nitte University, Deralakatte, Mangalore - 575 018, Karnataka, India. \\ E-mail : anupamaprasadd@ymail.com
}

\begin{abstract}
:
This article is an attempt to review all the articles available in English language on tissue conditioner in theliterature through $1996-2012$. A detailed search in the National Library of Medicine's PubM ed database, Google search and Science Direct to include all studies and reviews published in English language. This paper tries to give an overview of the composition, properties and uses of tissue conditioning materials.
\end{abstract}

Keywords: tissue conditioners; resilient denture reliners; soft lining materials; antifungals

\section{Introduction:}

In the present day scenario a lot of improvement in the field of medicine and research which has increased the life expectancy of the geriatric patients. Increased life expectancy combined with improved socialization has made people conscious about their appearance and performance in the society. There is a greater need for preservation of the remaining teeth and also for replacement of the lost teeth by an artificial substitute. The dentures are worn by the elderly for a time longer than needed with a minimum rest given to the bearing tissues.The increased wearing of dentures leads to irritation of the soft tissues, depriving it from blood supply and also leading to resorption of the supporting bony foundation. As a consequence, the denturestend to loosen demanding for the use of materials like tissue conditioners and denture adhesives to improve retention. Denture liner

Access this article online Quick Response Code

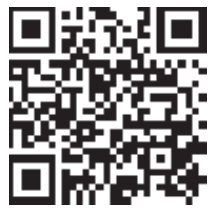
use in dentistry is not new and is known for many years now ${ }^{1}$.Resilient liners which were used previously were natural rubbers. In the year 1945,the first synthetic resin made of plasticized polyvinyl resins were developed and the silicone rubbers followed in $1958^{2}$.

\section{Uses of denture reliners:}

Denture reliners find several uses in the specialty of prosthodontics. They are used to improve fit of ill fitting dentures, to prevent traumatic damage to the mucosa, as a cushion between denture bearing mucosa and denture, to retain over denture bar attachments, to retain extra oral prosthesis, to distribute occlusal forces, to increase serviceable life of prosthesis, to replace the fitting surface of conventional hard dentures, to relieve mucosal pain under hard dentures, improves the rhythm of chewing strokes, it also compensates for the volumetric shrinkage of acrylic resin ${ }^{1,3,4,5}$.

\section{Desirable properties of lining materials:}

Long term viscoelastic behaviour which is stable, low water sorption, improved colour stability, resistance to staining, tearresistance, good bond strength to denture base, dimensionalstability, resistance to fungal and bacterialgrowth, ease of processing, good shelf life, biocompatibility, high magnitude of energy dissipation, good resiliency, low elastic modulus, heat resistance, low glass transition temperature, resistance to radiation, special rheological properties, outstanding electrical isolation ${ }^{1,5 \cdot 11}$. 


\section{Indications for the use of tissue conditioners:}

Thin atrophic mucosa underlying denture base, ridge atrophy or resorption, presence of deep anatomical undercuts, chronic bruxers or patients with bruxing tendencies, reduced tolerance level of the mucosa for occlusal loads under denture,acquired or congenital defects which require obturation, presence of bony protruberances, retention of implant retained overdentures ${ }^{12,13}$.

\section{Classification:}

\section{I.Based on curing ${ }^{5,9,14,15}$ :}

Self cure- eg.,soften, viscogel

Heat cure-eg.,supersoft,molloplast B, Lucisoft, Flexor, Permaflex

Light cure resins-eg.,clearfitLC(polyisoprene based material)

\section{Based on composition ${ }^{10,13,16,17,18,19,20 \text {; }}$}

Silicone elastomers

Soft acrylic compounds

Pthalate ester free compounds-eg.,di-n butyl sebacate,Benzyl benzoate, acetyl tributyl citrate,tri-n-butyl phosphate

Polyolefin liners

Fluoride containing liners(fluoroalkyl methacrylate)-eg., maxfit

\section{Based on durability ${ }^{14,16}$}

Temporary/Short term liners-eg., soft comfort

Definitive/long term liners

\section{Based on consistency}

Hard denture liners-eg.,Ufigel hard C

Soft denture liners-eg.,Silastic 390

Soft denture liners are further classified as a) silicone based and resin based b)Auto cured and heat cured

\section{Based on the availability ${ }^{21,22}$ \\ Home reliners}

Tissue conditioners

\section{Based on water sorption property ${ }^{9}$}

Hydrophilic- eg.,kooliner(polymethyl/ethyl methacrylate polymer)

Hydrophobic- eg.,Elite soft(silicone polymer)

\section{Composition:}

Powder of cold cure Acrylic based material consists of polyethyl methacrylate/copolymer, Polymethyl methacrylate/copolymer, benzoyl peroxide, pthalyl butyl glyconate, pigments, fillers ${ }^{23}$. Liquid contains methyl methacrylate, ethylene glycol dimethacrylate, ester plasticizer mixture like dibutyl phthalate, butyl pthalylbutylglycolate, benzyl butyl phthalate, dibutylsebacate, ethyl alcohol ${ }^{16,24,25}$. Heatcure liquid has in addition benzoyl peroxide initiator. Home reliners consist of polyvinyl acetate, ethyl alcohol, calcium carbonate, polypropylene glycol, white bees wax and alkyl methacrylate copolymers. Polypropylene glycol and wax allows for easy peeling of conditioners from dentures these along with alkyl methacrylate copolymer prevents adhesion to fingers. Polypropylene glycol also decreases the grip needed to squeeze liner from tube. White bees wax also acts as plasticizer ${ }^{20}$.Calcium carbonate increases elasticity of polymer. Liquid consists of acrylic, triacetyl citrate, trismethoxyethoxyvinylsilane. Silica consists of MDX (silastic M DX-4210) RTV silicone ${ }^{2}$, fumed silica with high surface area, hexamethyldisilanazane surface treatment to repel water, vinyl terminated polydimethylsiloxane, adhesive like 3-methacryloxypropyl trimethoxysilane and silicic acid ${ }^{11}$ Light cured material consists of urethane acrylate oligomers, benzoylperoxide ,camphoroquinone ${ }^{26}$.

\section{Gelation reaction:}

When the powder and liquid are mixed, polymer is dissolved by plasticizer. This reaction is responsible for chain entanglement and thus formation of gel. Since monomer is abscent, it is made of a non cross linked amorphous polymer $^{26}$.

\section{Loss of resiliency:}

When tissue conditioners are in continuous contact of 
liquids such as oral fluids, the plasticizer and alcohol contents leach out and water or saliva occupies these lacunae. The absorbed liquid acts like a plasticizer, lowering mechanical property of the polymer network, thus lowering the dynamic viscoelastic property. High molecular weight plasticizer leaches less compared to low molecular weight plasticizers. Silicone materials remain resilient for longer time because they are devoid of plasticizers. In addition they have greater cross linking and higher bonding capacity to the fillers ${ }^{26}$.

\section{Properties of liners:}

Water sorption by lining material leads to change in dimension and stress concentration at liner- denture base interface as a result leading to reduction of bond strength $^{1}$. Filler type and its bonding to the polymer is responsible for water absorption seen in RTV silicone. Heat cured silicone has better bond to filler and greater cross linking leading to the production of a denser material which are devoid of micro pockets of water within the material $^{27}$. The residual cross linking agent within the material also contributes to absorption of water. Plasticized acrylics have a better capacity to adhere to denture base but rapid plasticizer leaching from them leads to surface deterioration ${ }^{4}$.

Factors that affect the bond between acrylic and liner are: Geometry of bond surface whether roughened or clinically etched, use of bonding agents, inherent bond strength, compliance that varied, tear strength and thickness of lining materials ${ }^{5}$.Adhesives which are toluene based are weaker than those which are ethyl acetate solvent based. One of the main disadvantages of silicone is its lack of ability to bond to the acrylic denture base without an adhesive. Even if it succeeds to bond, the bond isseen to be week and less durable. On the other hand acrylic products have better bonding ability to the denture bases ${ }^{28,29}$.

Polyisoprene elastomers used as liners which are light cured materials show less water sorption compared to other varieties, softness which is moderate, superior stain resistance, adequate working time and advanced shear bond strength to denture base resins $s^{5}$. They show no leaching. Water absorption of silicone materials compared to plasticized acrylics was less ${ }^{30}$. Those of heat cured materials were less than that of cold cured materials. High rates of water sorption and solubility can lead to changes in dimension, loss of colour, resiliency, bond and also to development of unpleasant odors.

Gammamethacryloxypropyltrimethoxysilane type heatpolymerized silicone rubbers like Molloplast- B (Buffalo Dental Manufacturing, Syosset, NY) showed prolonged service as liners. Where in the reaction is seen between curing agent and reactive groups of the polymer and allows methacrylate groups bond with the polymethyl methacrylate denture base material ${ }^{31}$. Presence of porosities and irregularities lead to detachment of soft liner from acrylic resin surface, thus weakening the bond and increasing concentration of stress ${ }^{22}$.

Improvement in bond strength of liners and acrylics was experimented through introduction of roughness of acrylic interface with the aid of lasers, alumina abrasion, chemical etch (chemical etchants such as MMA, acetone, or methylene chloride are used to increase the bond strength of repair material to PMMA), acrylic burs, chemical primers, reinforcement of the acrylic surfaces with net woven fibers of glass ${ }^{1}$.Oxygen plasma treatment wherein gaseous mixtures of free radicals, ions, electrons, and excited molecular states are created by inelastic collisions between high energy electrons and ground state atoms or molecules. This improves the hydrophilicity of inner surfaces at the same time since it is bonded immediately after treatment it maintains the surface hydrophobicity of the surface ${ }^{32}$.

Fillers such as silica can be the cause for the demonstration of high water absorption in soft lining materials $s^{33}$.Silane treated silica when used showed less water sorption. Higher cross linking shows lower tear since it reduces segmental mobility of polymeric chains. Higher filler concentration, their grade and a strong bond between filler and polymer also increases tear strength ${ }^{34,35}$. Lower water sorption and solubility were seen in a novel product fluoroalkyl methacrylate-based denture liner (M axfit) ,a 
fluoride containing liner material this property is due to Fluorine atoms as they produce a low-energy surface, which is water- and oil-shedding but have decreased mechanical strength ${ }^{36}$. Water sorption can be decreased by application of a sealer as a mechanical barrier ${ }^{37}$. Decreased number of hydrocarbon groups within polymers leads to increased hydrophilicity ${ }^{38}$. Discoloration of denture base materials is observed after long-term use. Factors responsible may be accumulation of stain, sorption of water, dissolution of ingredients and intrinsic pigments degradation. Beverages such as tea which contain flavanoids and methylxanthine, coffee which contain nicotine, caffeine and caffeic acid wine, artificial dyes as part of food, smoking and microbial colonization and pigments in the liner also contribute for discoloration ${ }^{5,34,39,40}$. Less change of color and improved resistance to staining were seen with the fluorinated soft lining materials ${ }^{6}$.M ore colour change is seen in Hydrophobic and pigmented liners. Leaching of plasticizers creates space which incorporates staining pigments which is accentuated by rough surfaces ${ }^{34}$.

Properties of denture lining materials such as stress relaxation and softness varied under cyclic loading conditions. Softness value increased on loaded or stored period and the stress relaxation increased as increase in thickness of the lining materials from $1 \mathrm{~mm}$ to $3 \mathrm{~mm}$. Superior resistances to flow and the higher elasticity is a result of cross-linked polymer structure ${ }^{41}$. Presence of unpolymerized layer easily stains the liners, curing temperature, powder/liquid ratio is responsible for thickness of the layer. Presence of reducing agent makes heat-polymerized resins superior in color stability compared to relining in addition to low conversion of the monomer component and penetration of colored substances present in the oral environment. Use of postrelining heat treatment and surface hardening or oxygeninhibiting agents improves monomer conversion. Also the surface to be relined can be ground and conditioned with dichloromethane to improve bond between relining material and PM M A ${ }^{42}$.
Anti fungal can be incorporated into tissue conditioners. There are several advantages of tissue conditioners wit incorporated antifungal such as reduced treatment cost, patient compliance is not required, Simultaneous treatment of both injured tissues and Candida infection possible, reduced frequency of application of antifungal. At the same time mechanical properties like increased tensile strength, reduces hardness and modulus of elasticity. The drug delivery feature depends on certain factors like, molecular weight, particle size, distribution and concentration within the matrix, dissolution diffusion properties, permeability, porosity and matrix-drug interactions ${ }^{43}$.

\section{Discussion:}

In the modern society where socialization is important and where elderly patients want to look younger and carry a beautiful smile, there is a great demand for prosthetic replacement of lost teeth may be single or multiple. As there is a natural tendency of remodeling of bone based on the tension and pressure applied on it in the form of denture bases and occlusal loads, there seems to be loosening of the denture bases. Proper fit of the prosthesis is a must for proper functioning of speech and mastication, besides maintenance of esthetics. Application of tissue conditioner serves this purpose very well. Most of the time patients are given complete dentures with balanced occlusion so that there is very less detrimental effect to the underlying tissues. As the remodeling process continues, balanced occlusion is lost and tissue conditioners can help in covering up these unwanted changes by stabilizing the denture bases.

Tissue conditioners have seen great change in composition over the years. There is advancement in material science from hard acrylic liners to the newer silicone based liners. $M$ aterials like anti fungals were incorporated into the liners for prevention of fungal growth in the moist oral cavity. There is now a need to incorporate harmless herbal extracts into the liners to prevent side effects and also to overcome development of resistance to the commercially available antifungal agents by the candidalspecies. 
Bonding of the conditioning materials to denture base material is seen as a major problem in addition to staining and biofilm development. Bonding is improved by surface modification Biofilm development is tried to overcome by applying a sealer onto the surface of conditioner. Hydrophobic tissue conditioners are also available. Whatever may be the type of tissue conditioners, there is no doubt that it is a healing magician to the abused tissues under the hard denture bases.

\section{Conclusion:}

Though a material of short term use, tissue conditioning materials has a vast importance in the field of Prosthodontics. It takes care of abused tissues well and recently many research works have been carried out in order to incorporate anti fungals into these with high

\section{References:}

1. Hatamleh M M, Maryan CJ, Silikas N, Watts DC.Effect of net fiber reinforcement surfsce treatment on soft denture liner retention and longevity.J Prosthodont. 2010;19(4):258-62.

2. Mese A, Guzel KG.Effect of storage duration on the hardness and tensile bond strength of silicone- and acrylic resin-based resilient denture liners to a processed denture base acrylic resin.J Prosthet Dent. 2008;99(2):153-9.

3. Hatamleh M M , Rodrigues FP, Silikas N, Watts DC.3D-FE analysis of soft liner-acrylic interfaces under shear loading.Dent $M$ ater. 2011;27(5):445-54.

4. Jepson NJ, McCabe JF, Basker RM.A new temporary soft lining material.J Dent. 1995;23(2):123-6.

5. Hayakawa I, Keh ES, Morizawa M, Muraoka G, Hirano S.A new polyisoprene-based light-curing denture soft lining material.J Dent.2003;31(4):269-74.

6. Kasuga Y, Takahashi H, Akiba N, M inakuchi S, Matsushita N, Hishimoto M.Basic evaluation on physical properties of experimental fluorinated soft lining materials. Dent M ater J. 2011;30(1):45-51.

7. Waters M, Jagger R, Williams K, Jerolimov V. Dynamic mechanical thermal analysis of denture soft lining materials.Biomaterials. 1996; 17(16): 1627-30.

8. Santawisuk W, Kanchanavasita W, Sirisinha C, Harnirattisai C.Dynamic viscoelastic properties of experimental silicone soft lining materials.Dent M ater J. 2010;29(4):454-60.

9. Leite VM , Pisani MX, Paranhos HF, Souza RF, Silva-Lovato CH. Effect of ageing and immersion in different beverages on properties of denture lining materials.J Appl Oral Sci. 2010;18(4):372-8.

10. Hayakawa I, Akiba N, Keh E, Kasuga Y. Physical properties of a new denture lining material containing a fluoroalkyl methacrylate polymer. J Prosthet Dent 2006;96(1):53-8

11. Dogan OM, Keskin S, Dogan A, Ataman H, Usanmaz A. Structure - Property relation of a soft liner material used in denture applications. Dental M aterials J ournal 2007;26(3):329-34.

12. Pavan S, dos Santos PH, Filho JN, Spolidorio DM . Colonisation of soft lining materials by micro-organisms. Gerodontology 2010; 27(3): 211-6.

13. Savabi O, Ataei E, Khodaeian N. Fabricating a Soft Liner-Retained Implant-Supported Palatal Lift Prosthesis for an Edentulous Patient: A molecular weight which can release anti fungals to the tissues at regular intervals but in small quantities. Introduction of nano particles into the denture base materials is also under study. Denture liner properties are exploited to maximum to relieve symptoms of abused tissues. Propermaintenance of oral hygiene and incorporation of methods to make the surface resistant to staining also should be considered. Bonding is one of the major problems seen with tissue conditioners. Even this problem is addressed by modifying the surface of resin denture base by methods which improve mechanical locking and also increase the surface area. Silicone materials require adhesives for bonding. Tissue conditioners have proven a very useful material in terms of improving fit of old dentures and restoring tissues to normal health.

Case Report.Case Rep Dent. 2012;2012:203547. doi: 10.1155/2012/203547. Epub 2012 Jun 19.

14. Goiato M C, Zuccolotti BC, M oreno A, dos Santos DM, Pesqueira AA, Dekon SF. Colour change of soft denture liners after storage in coffee and coke. Gerodontology 2011; 28(2): 140-145

15. Vural C, Ozdemir G, Kurtulmus H, Kumbuloglu O, Ozcan M Comparative effects of two different artificial body fluids on Candida albicans adhesion to soft lining materials.Dent Mater J. 2010;29(2):206-12

16. Murata H, Chimori H, Hong G, Hamada T, Nikawa H. Compatibility of tissue conditioners and denture cleansers: Influence on surface conditions.Dent M ater J. 2010;29(4):446-53.

17. Hashimoto Y, Nakamura M. Cytocompatibility and viscoelastic properties of phthalate ester-free tissue conditioners. Dent M ater J. 2004;23(3):412-8

18. Nishijima M, Hashimoto $Y$, Nakamura M. Cytocompatibility of new phthalate ester-free tissue conditioners in vitro. Dent M ater J. 2002 ;21(2):118-32.

19. Riggs PD, Parker S, Braden M, Kalachandra S. Development of butyl elastomer/methacrylate monomer systems as denture soft lining materials. Biomaterials.2002;23(3):915-920.

20. Abe Y, Taji T, Hiasa K, Tsuga K, Akagawa Y. Dynamic viscoelastic properties of vinyl polysiloxane denture soft lining materials. J Oral Rehabil. 2009:36(12):887-93.

21. Murata H, Hong G, Yamakado C, Kurogi T, Kano H, Hamada T. Dynamic viscoelastic properties,water absorption and solubility of home reliners.Dent M ater J. 2010;29(5):554-61.

22. Takahashi JM, Consani RL, Henriques GE, Nóbilo MA, M esquita M F Effect of accelerated aging on permanent deformation and tensile bond strength of autopolymerizing soft denture liners. J Prosthodont. 2011;20(3):200-4.

23. Waters M GJ, Jagger RG, Winter RW. Effect of surface modified fillers on the water absorption of a (RTV) silicone denture soft lining material. J. Dent. 1996; 24(4):297-300.

24. Brozek R, Koczorowski R, Rogalewicz R, Voelkel A, Czarnecka B, Nicholson JW. Effect of denture cleansers on chemical and mechanical behavior of selected soft lining materials.Dent M ater. 2011;27(3):28190. 
25. Hong G, M aeda T, M urata H, Sasaki K.The dynamic viscoelasticity and plasticizer leachability of tissue conditioners. Gerodontology 2012; 29(4): 284-91.

26. Kanie T, Kadokawa A, Arikawa H, Fujii K, Ban S. Effects of adding methacrylate monomers on viscosity and mechanical properties of experimental light-curing soft lining materials based on urethane (meth)acrylate oligomers. Dent M ater J. 2008;27(6):856-61.

27. Waters M GJ, Jagger RG, Winter RW. Water absorption of (RTV) silicone denture softlining material. . . Dent. 1996; 24: 105-8.

28. M cCabe JF. A polyvinylsiloxane denture soft lining material. J Dent. $1998 ; 26(5) 521-6$

29. McCabe JF, Carrick TE, Kamohara H. Adhesive bond strength and compliance for denture soft lining materials. Biomaterials. 2002 ;23(5):1347-52.

30. DinçkalYanikoglu N, Denizoglu S. An investigation of the tear energy of five soft lining materials.Dent M ater J. 2003;22(4):444-51.

31. Villar A, Pesun IJ, Brosky ME, Fines C, Hodges JS, DeLong R, Lai JH.Clinical evaluation of a new resilient denture liner. Part 1 : Compliance and color evaluation. J Prosthodont 2003;12(2):82-9.

32. Zhang H, Fang J, Hu Z, M a J, Han Y, Bian J. Effect of oxygen plasma treatment on the bonding of a soft liner to an acrylic resin denture material.Dent M ater J. 2010;29(4):398-402.

33. Waters MG, Jagger RG. Mechanical properties of an experimental denture soft lining material. J Dent.1999;27(3):197-202.

34.Oguz S, M utluay M M, Dogan OM , Bek B. Colour Change Evaluation of Denture soft lining materials in Coffee and tea.Dent Mater J. 2007;26(2):209-16.

35. Hayakawa I, Akiba N, Keh E, Kasuga Y. Physical properties of a new denture lining material containing a fluoroalkyl methacrylate polymer.
J Prosthet Dent 2006;96(1):53-8

36. Mainieri VC, Beck J, Oshima HM, Hirakata LM, Shinkai RS. Surface changes in denture soft liners with and without sealer coating following abrasion with mechanical brushing. Gerodontology 2011; 28(2): 146-51

37. Hong G, Tsuka H, Maeda T, Akagawa Y, Sasaki K.The dynamic viscoelasticity and water absorption characteristics of soft acrylic resin materials containing adipates and a maleate plasticizer .Dent Mater J.2012;31(1):139-49.

38. Sarac D, Sarac YS, Basoglu T, Yapici O, Yuzbasioglu E.The evaluation of microleakage and bond strength of a silicone-based resilient liner following denture base surface pretreatment.J Prosthet Dent 2006;95(2):143-51.

39. Bal BT, Yavuzyilmaz H, Yücel M .A pilot study to evaluate adhesion of oral microorganisms to temporary soft lining materials.J Oral Sci. 2008;50(1):1-8.

40. Imirzalioglu P, Karacaer O, Yilmaz B, OzmenM sc I.Color Stability of Denture Acrylic Resins and a Soft Lining M aterial Against Tea, Coffee, and Nicotine.J Prosthodont. 2010;19(2):118-24.

41. Cha HS, Yu B, Lee YK.Changes in stress relaxation property and softness of soft denture lining materials after cyclic loading.Dent M ater. 2011 :27(3):291-7.

42. M atsumura H, Tanoue N, Kawasaki K\& Atsuta M. Clinical evaluation of a chemically cured hard denture relining material. J Oral Rehabil. 2001; 28: $640-4$.

43. Urban VM, Seó RS, Giannini M, Arrais CA.Superficial Distribution and Identification of Antifungal/Antimicrobial Agents on a M odified Tissue Conditioner by SEM-EDS Microanalysis: A Preliminary Study. J Prosthodont. $2009 ; 18(7): 603-10$ 